\title{
Impairment of social behaviors in Arhgef10 knockout mice
}

\author{
Dai-Hua Lu', Hsiao-Mei Liao², Chia-Hsiang Chen, ${ }^{3,4}$ Huang-Ju Tu' , Houng-Chi Liou', Susan Shur-Fen Gau ${ }^{2 *}$ \\ and Wen-Mei Fu ${ }^{*}$
}

\begin{abstract}
Background: Impaired social interaction is one of the essential features of autism spectrum disorder (ASD). Our previous copy number variation (CNV) study discovered a novel deleted region associated with ASD. One of the genes included in the deleted region is ARHGEF10. A missense mutation of ARHGEF10 has been reported to be one of the contributing factors in several diseases of the central nervous system. However, the relationship between the loss of ARHGEF10 and the clinical symptoms of ASD is unclear.
\end{abstract}

Methods: We generated Arhgef10 knockout mice as a model of ASD and characterized the social behavior and the biochemical changes in the brains of the knockout mice.

Results: Compared with their wild-type littermates, the Arhgef10-depleted mice showed social interaction impairment, hyperactivity, and decreased depression-like and anxiety-like behavior. Behavioral measures of learning in the Morris water maze were not affected by Arhgef10 deficiency. Moreover, neurotransmitters including serotonin, norepinephrine, and dopamine were significantly increased in different brain regions of the Arhgef10 knockout mice. In addition, monoamine oxidase A (MAO-A) decreased in several brain regions.

Conclusions: These results suggest that ARHGEF10 is a candidate risk gene for ASD and that the Arhgef10 knockout model could be a tool for studying the mechanisms of neurotransmission in ASD.

Trial registration: Animal studies were approved by the Institutional Animal Care and Use Committee of National Taiwan University (IACUC 20150023). Registered 1 August 2015.

Keywords: ARHGEF10, Autism spectrum disorder, Social deficits, Serotonin, Norepinephrine

\section{Background}

Autism spectrum disorder (ASD) is a common neurodevelopmental disorder marked by lifetime social functional impairment $[1,2]$. The essential features of ASD include impairment in reciprocal social communication; a deficit in communication ability; and restricted, repetitive behavior and interests [1]. ASD occurs at a higher incidence in males than females, with a common consensus ratio of 4:1 [3]. The prevalence of ASD has been estimated at approximately $1.5 \%$ and has increased dramatically over the past few decades $[4,5]$. Various genetic studies have provided convincing evidence that ASD is a complex and highly

\footnotetext{
* Correspondence: gaushufe@ntu.edu.tw; wenmei@ntu.edu.tw

${ }^{2}$ Department of Psychiatry, National Taiwan University Hospital and College

of Medicine, Taipei, Taiwan

${ }^{1}$ Pharmacological Institute, College of Medicine, National Taiwan University,

Taipei, Taiwan

Full list of author information is available at the end of the article
}

polygenic disease [6]. However, the genetic underpinnings of ASD remain unclear, which impedes understanding of the disease pathology and the search for treatments.

Our previous study identified two novel chromosomal deletions in two unrelated ASD patients [7]. One of the deletions, which spans 8p23.3-pter, contains three genes--DLGAP2, CLN8, and ARHGEF10--that may be relevant to neurological functions. The functional loss of these genes might contribute to the clinical symptoms of ASD $[8,9]$. In this study, we target the gene ARHGEF10 to further investigate the impacts of its functional loss. ARHGEF10, as a rho guanine nucleotide exchange factor (GEF), regulates rho GTPases by catalyzing the exchange of G-protein-bound GDP for GTP. There are over 60 rho GEFs identified in the human genome. However, few have been functionally evaluated in animal models. The Thr109lle mutation of the rho GEF 10 (ARHGEF10) 
gene was found in a family of patients with slow nerve conduction and thinly myelinated peripheral nerves [10]. In addition to its possible role in the myelination process, the single nucleotide polymorphism of ARHGEF10 has also been reported to be associated with schizophrenia [11]. GEFs are the main regulators that facilitate the activation of rho GTPases by converting them from the GDP-bound state to an active GTPbound state. Rho GTPases have been widely studied in neuronal development and neuronal diseases [12]. Given the importance of rho GTPases in the nervous system, dysregulation of rho GEFs is believed to be involved in neurodevelopmental diseases. For example, a mutation of ARHGEF6 has been associated with intellectual disability [13]. These findings encouraged us to further study the possible role of ARHGEF10 in ASD.

To explore the role of ARHGEF10 in ASD and to further understand the impacts of ARHGEF10 deletion on the molecular mechanisms of neurological function, we generated an Arhgef10 knockout mouse model by deleting exons 4 and 5 of the mouse Arhgef10 gene. The mice without the Arhgef10 gene have normal fertility and body weight gain. The Arhgef10 knockout mice were then subjected to tests measuring their startle responses, motor behavior, spatial learning, and social behavior. Behavioral changes may reflect a disturbance of neurotransmission. Previous studies have shown that the dysregulation of biosynthesis, transportation, and degradation of neurotransmitters could be associated with ASD [14]. In addition, genetic association studies have identified some genes that encode the transporters or degradation enzymes of neurotransmitters as contributing to the risk of ASD [15]. For instance, monoamine oxidase A (MAO-A), an enzyme that is important for the metabolism of serotonin and norepinephrine, is associated with ASD in a population-based study [15]. Another population-based association study also indicates that changes in monoamine oxidase $\mathrm{B}$ (MAO-B) activity increase ASD risk in males [16]. Based on those findings, we evaluated the levels of monoamines in Arhgef 10 knockout mice to understand the possible roles of Arhgef10 in the serotonergic system.

In this study, we found that Arhgef10 knockout mice exhibited impaired social interaction and social recognition, representing the key characteristics of ASD. In addition, Arhgef10 knockout mice also displayed reduced anxiety-like and depression-like behaviors and increased locomotor activity. Additionally, serotonin, norepinephrine, and dopamine were elevated in the frontal cortex, hippocampus, and amygdala in Arhgef10 knockout mice. Moreover, MAO-A, a molecule that regulates the levels of certain neurotransmitters, was also reduced in Arhgef10 knockout mice. Behavioral studies and biochemical examination showed that ARHGEF10 not only plays a critical role in social behavior but also participates in the regulation of neurotransmitters.

\section{Methods \\ Animals and experimental design}

Arhgef10 knockout mice were generated by the deletion of exon 4 and exon 5 using the Cre-loxP site-specific knockout according to a method described previously [8]. The strategy for generating Arhgef10 knockout mice is shown in Additional file 1: Figure S1. In brief, exons 4 and 5 of ARHGEF10 in embryonic stem cells from the $129 \mathrm{~S} 1 / \mathrm{Sv}$ mouse strain were replaced with a construct containing ARHGEF10 exons 4 and 5 interposed between two loxP sites and a NEO cassette to produce Cre-induced homologous recombination. Arhgef10 knockout mice were then backcrossed for at least ten generations with C57BL/6J mice. The Arhgef10 knockout mice used in this study were produced by heterozygous breeding pairs in a trio breeding format. All mice were kept under standard temperature, humidity, and timed lighting conditions and provided with mouse chow and water ad libitum. Arhgef10 knockout mice and their control littermates were housed in groups (3-5 mice per cage).

Behavioral tests were conducted during the light cycle (07:00-19:00) in a testing room next to the mouse housing room. Eight- to twelve-week-old male Arhgef10 KO mice and their WT littermates were used in this study. All behavioral tests were carried out with male mice. Animals in the same littermates were used in the same behavioral test, except for the plus maze, open field, and water maze tests. In these three tests, the intervals between tests were approximately 7 days each. The open field test was conducted first, followed by the plus maze and then the water maze. Mice were transported to the testing room and habituated for $30 \mathrm{~min}$ before behavioral testing. All animal experiments were approved by the Ethical Committee for the Animal Research of National Taiwan University.

\section{Sample preparation}

Mice were anesthetized with isoflurane and then decapitated. For Nissl staining, the brains of 10-week-old mice were removed after saline perfusion and post-fixed with $4 \%$ paraformaldehyde (PFA) overnight. Tissue samples for Western blots and high-performance liquid chromatography (HPLC) were prepared by dissecting four parts from the fresh brains of 10- to 12-week-old mice: frontal cortex, striatum, hippocampus, and amygdala. These tissues were then weighed and homogenized.

\section{Nissl staining}

Nissl staining was performed as previously described [17]. In brief, $40-\mu \mathrm{m}$-thick frozen brain sections from 
WT and Arhgef10 knockout mice were mounted on gelatin-coated slides and air-dried overnight. The slices were then placed directly into xylene for $3 \mathrm{~min}$ and then rehydrated with 100,95 , and $85 \%$ alcohol, followed by distilled water. The slices were stained with $0.02 \%$ crystal violet (Sigma-Aldrich, St. Louis, MO, USA) solution for 25-35 $\mathrm{min}$ and then rinsed quickly in distilled water. Finally, the slices were soaked in xylene and mounted with permanent mounting medium.

\section{Open field test}

Mice were placed in an open plastic chamber $(40 \times 40 \times$ $38 \mathrm{~cm}$ ), and locomotor activity was monitored for $1 \mathrm{~h}$. The central region of the open field was defined as a region of $20 \times 20 \mathrm{~cm}^{2}$, and all activity was measured by a $16 \times 16$ photobeam sensor connected to an automated tracking program (PAS-Open Field, San Diego Instruments). The number of beam breaks were used as an indicator of locomotor activity.

\section{Elevated plus maze test}

The elevated plus maze (EPM) apparatus (made of white Plexiglas) was elevated $40 \mathrm{~cm}$ above the floor and consisted of two open arms alternating with two closed arms. The open arms and closed arms were made of plastic and measured $25 \mathrm{~cm}$ long $\times 5 \mathrm{~cm}$ wide. The two closed arms were protected by $15-\mathrm{cm}$-high walls. Mice were placed in the EPM for $5 \mathrm{~min}$, and the time spent in each arm and frequency of entry into each arm were recorded by Noldus EthoVision 3.0 (EthoVision', Noldus Information Technology).

\section{Tests for sociability and social novelty preference in a three-chamber apparatus}

The tests for sociability and social novelty preference were performed in a three-chamber apparatus as previously described with minor modification $[18,19]$. The animals used here were all age- and sex-matched littermates; $\mathrm{C} 57 \mathrm{BL} / 6 \mathrm{~J}$ mice were used as the stranger mice. All animals were habituated to the test chamber for $30 \mathrm{~min} 1$ day before the behavioral test. The threechamber apparatus was a $21 \mathrm{~cm}$ (height) $\times 25 \mathrm{~cm}$ (width) $\times 48 \mathrm{~cm}$ (length) black plastic box. Before the sociability test, the animal was free to explore the apparatus for $5 \mathrm{~min}$. In the sociability test session, an unfamiliar same-sex mouse, designated as stranger 1, was placed in the plastic cylinder; an empty cylinder was placed in the opposite chamber. The cylinders $(13 \mathrm{~cm}$ in height, $10 \mathrm{~cm}$ in diameter) were transparent, and their walls contained holes that allowed the mice to sniff each other. The test mouse was placed in the central chamber and allowed to freely explore these three chambers for $10 \mathrm{~min}$. In the social novelty preference test, a second novel mouse, stranger 2, was placed in the opposite chamber, which was empty in the previous session. The test mouse was allowed to freely explore the chambers for $10 \mathrm{~min}$ in this session. The time spent in each chamber and the time spent sniffing or interacting with the stranger mouse were recorded. In addition, the number of entries into all chambers were analyzed using EthoVision.

\section{Tail suspension test and forced swim test}

The tail suspension test (TST) [20] and the forced swim test (FST) are the most commonly used tests to evaluate depression-like behavior in rodents. In the TST, the animals were suspended by the tail with adhesive tape for $6 \mathrm{~min}$. In the FST, the animals were placed in a plastic cylinder tank $(30 \mathrm{~cm}$ in height $\times 15 \mathrm{~cm}$ in diameter) filled with $25 \pm 2{ }^{\circ} \mathrm{C}$ water for $6 \mathrm{~min}$. The complete TST and FST sessions were all videotaped for analysis. Immobility was defined as a lack of motion of the whole body at 2-6 min, when the mice ceased struggling and began passively floating, making only the movements necessary to keep the head above water.

\section{Pre-pulse inhibition test}

Pre-pulse inhibition (PPI) was tested in an acoustic startle chamber (SR Lab, San Diego Instruments, San Diego, CA). The chamber contained a Plexiglas cylinder $(12.6 \mathrm{~cm}$ in length $\times 4.0 \mathrm{~cm}$ in internal diameter) fixed on a platform under which a piezoelectric accelerometer recorded and transduced the motion of the tube. The sensor transmitted the digitized signals to a computer interfaced with the startle apparatus. To provide a consistent acoustic environment and mask external noise, we maintained a continuous background of $65-\mathrm{dB}$ white noise within each chamber throughout the PPI tests. The inter-trial interval was between 10 and $20 \mathrm{~s}$. Each startle trial consisted of a single $120-\mathrm{dB}$ white noise burst lasting $40 \mathrm{~ms}$. Each PPI trial consisted of a prepulse $(20 \mathrm{~ms}$ burst of white noise with an intensity of 70 , 74 , or $82 \mathrm{~dB}$ ) followed by the startle stimulus $100 \mathrm{~ms}$ later $(120 \mathrm{~dB}, 40 \mathrm{~ms}$ of white noise). Each of the three types of pre-pulse trials $(70,74$, and $82 \mathrm{~dB}$ ) was presented 10 times. The percentage of PPI was calculated according to the following formula: \%PPI $=(\mathrm{S}-(\mathrm{P}+\mathrm{S}))$ / $\mathrm{S} \times 100 \%$, where $\mathrm{P}+\mathrm{S}$ is the recorded response amplitude for pre-pulse plus startle pulse trials, and $\mathrm{S}$ is the recorded response amplitude for startle pulse-only trials.

\section{Morris water maze test}

Spatial learning was evaluated behaviorally using the Morris water maze. The maze consisted of a circular pool of water, $105 \mathrm{~cm}$ in diameter and $21 \mathrm{~cm}$ in height. The pool was divided into four equal quadrants: the target zone, two adjacent zones, and the opposite zone. The pool was filled with water at $22 \pm 0.5{ }^{\circ} \mathrm{C}$. A circular 
platform of $10 \mathrm{~cm}$ diameter was placed at the center of the target quadrant, and approximately $1.5 \mathrm{~cm}$ below the surface of the water. The maze was surrounded by four simple visual cues external to the maze. The movements of the mice were recorded with a video camera placed on the ceiling over the center of the maze, and the paths of the mice were analyzed using EthoVision. The training was started by acclimating the mice to the task environment with 1 day of free swimming in the pool without the platform. Each mouse underwent four consecutive training trials per day for 4 days. In each trial, the mice were placed along the edge of one quadrant of the maze; all quadrants except the target quadrant were used as starting locations. The duration from the time when the mouse entered the water until it climbed onto the platform was recorded as escape latency, and the mean latency to find the hidden platform was calculated for each individual mouse on each day. The maximum duration of each trial was $1 \mathrm{~min}$, and the mice were removed from the pool by the experimenter after each trial. If the mice failed to find the platform within $1 \mathrm{~min}$, they would be placed on the platform, where they were allowed to remain for $15 \mathrm{~s}$. For the probe trial, $24 \mathrm{~h}$ after the final trial, the platform was removed. Each mouse was placed in the water maze at the edge of the former platform location and allowed to swim freely for $60 \mathrm{~s}$. The total time that each mouse spent in each quadrant of the tank was recorded.

\section{High-performance liquid chromatography}

The levels of serotonin, norepinephrine, and dopamine in the frontal cortex, striatum, hippocampus, and amygdala were measured by HPLC analysis. Four different mouse brain areas were dissected from the cerebral hemisphere, weighed, and homogenized in $0.1 \mathrm{~N}$ perchloric acid by sonication. The homogenates were then centrifuged at $14,500 \times g$ for $30 \mathrm{~min}$ at $4{ }^{\circ} \mathrm{C}$, and the supernatants were collected for HPLC analysis. HPLCECD (Sykam, Gilching, Germany) was used to evaluate levels of monoamines, including dopamine, 5-HT, and $\mathrm{NE}$ and their metabolites, in the samples $(20 \mu \mathrm{l})$. The chromatogram peaks corresponding to the monoamines were identified by their retention times compared with the elution times of monoamine standards (Sigma, St. Louis, MO). The levels of dopamine, 5-HT and NE, were then estimated by the ratios of the peak heights to those of the internal standards and expressed as nanograms of neurotransmitter per gram of tissue.

\section{Western blotting}

Western blot analysis was performed to characterize ARHGEF10 (Proteintech Group, IL, USA; 11112-1-AP), GAPDH (Santa Cruz, Dallas, TX, USA; sc25778), $\beta$-actin (Sigma-Aldrich, St. Louis, MO, USA; A5316), MAO-A
(Abcam, Cambridge, UK; ab126751), monoamine oxidase B (MAO-B) (Abcam, Cambridgeshire, UK; ab137778), dopamine $\beta$-hydroxylase ( $\mathrm{D} \beta \mathrm{H})$ (Abcam, Cambridge, UK; ab108384), and tryptophan hydroxylase (TPH) (Abcam, Cambridge, UK; ab52954) expression in the brains of WT and ARHGEF10 knockout mice. Mouse brain tissues were lysed in RIPA buffer $(150 \mathrm{mM} \mathrm{NaCl}, 50 \mathrm{mM}$ Tris-HCl, $1 \mathrm{mM}$ EGTA, 1\% Nonidet P-40, 0.25\% deoxycholate, $1 \mathrm{mM}$ sodium fluoride, $50 \mathrm{mM}$ sodium orthovanadate) supplemented with Halt protease inhibitor cocktail (Thermo, IL, USA). Proteins were separated by SDSPAGE, transferred to PVDF membranes, and blocked with $5 \%$ non-fat milk for $1 \mathrm{~h}$. The membranes were then incubated with primary antibodies at $4{ }^{\circ} \mathrm{C}$ overnight followed by the appropriate secondary antibodies at room temperature for $1 \mathrm{~h}$. The protein bands were visualized using enhanced chemiluminescence (ECL) (Millipore, MA, USA) reagent, and blot images were captured using a UVP imaging system with LabWorks Software (Upland, CA, USA).

\section{Data analysis}

Throughout the study, parametric analysis was performed by one- or two-way ANOVA, using a between-group factor of genotype and a within-group factor of each behavioral parameter. If the overall ANOVA showed a significant difference, Tukey's test was used for post hoc comparisons. Statistical analysis was conducted using SPSS (IBM Inc., Somers, NY, USA) and GraphPad Prism (San Diego, CA, USA) software. Graphs of the data were also created using GraphPad Prism. The data were represented as the mean \pm standard error.

\section{Results}

\section{ARHGEF10 expression in different brain regions}

To examine ARHGEF10 expression in the central nervous system, we measured the protein level by Western blot analysis. As shown in Fig. 1a, ARHGEF10 protein was widely expressed in the wild-type (WT) mouse brain, especially in the frontal cortex and amygdala. Notably, the absence of ARHGEF10 protein in the knockout mouse brain was confirmed by Western blotting (Fig. 1b). Nissl staining of serial coronal brain sections revealed a similar brain structure between WT and Arhgef10 knockout mice (Fig. 1c).

\section{Arhgef10 knockout mice display social deficits in the three-chamber test}

To explore whether Arhgef10 knockout affects social interaction, we employed the three-chamber paradigm to test sociability and social recognition. After habituation, a novel same-sex mouse was placed within the plastic cylinder (stranger mouse 1) in one chamber, and one empty cylinder was placed in another chamber. We found that WT mice 


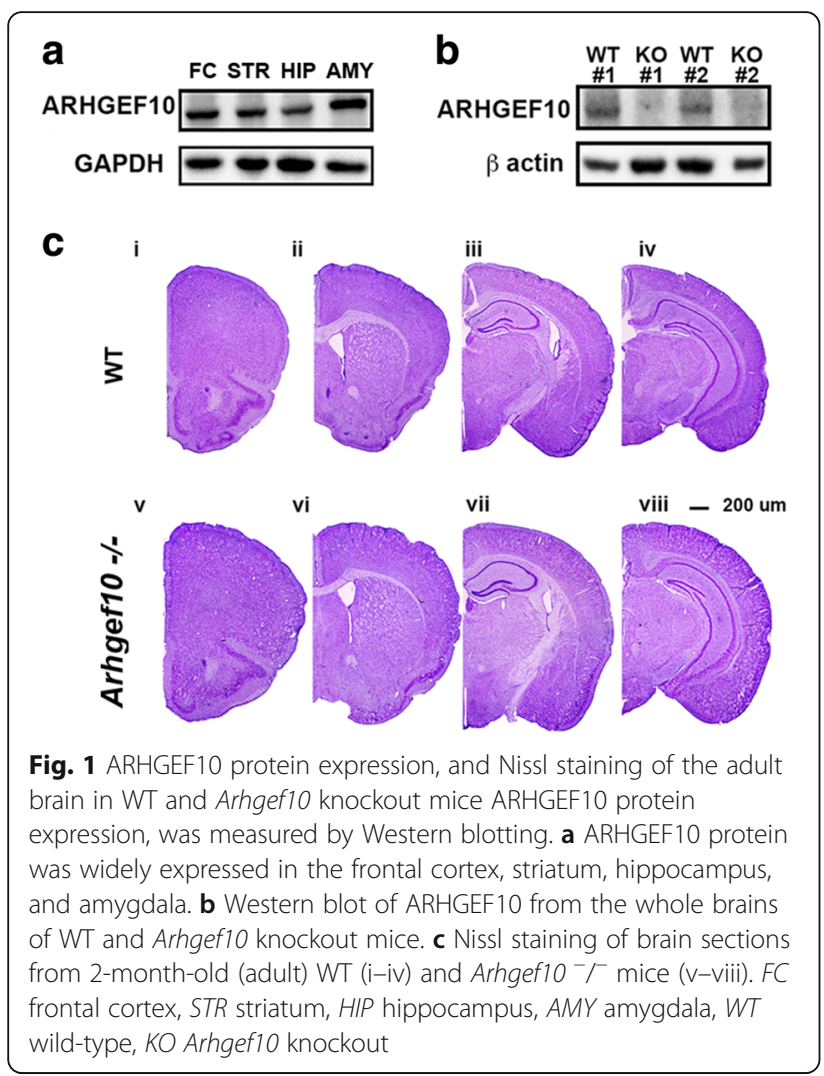

spent a significantly longer time in the chamber with a stranger mouse than in the empty chamber (Fig. 2a; $F_{1,22}=$ 36.517, $p<0.001$ for genotype $\times$ chamber by two-way ANOVA; $F_{1,22}=24.831, p<0.001$ for chamber; Tukey's post hoc comparisons were used to examine the differences between the empty cylinder and stranger mouse 1, WT: $p$ $<0.05$; KO: $p>0.05 ; n=12$ for each). However, Arhgef10 knockout mice did not spend a longer time in the chamber with the stranger mouse (Fig. 2a). Upon further evaluation of the social interactions, we found that WT mice spent significantly and markedly more time in close interaction with the stranger mouse by sniffing the holes of the cylinder, indicating normal social ability (Fig. $2 \mathrm{~b} ; F_{1,22}=52.971$, $p<0.001$ for genotype $\times$ chamber by two-way ANOVA; $p<$ 0.05 for post hoc comparisons between the empty cylinder and the stranger mouse, $n=12$ ). Arhgef10 knockout mice showed no significant preference between these two cylinders, indicating that they did not exhibit interest in the stranger mouse (Fig. 2b; $p>0.05$ for post hoc comparisons between the empty cylinder and the stranger mouse, $n=$ 12). Since enhanced locomotor activity may increase the possibility of contacts between mice, we further examined the number of entries into each chamber. We found that the number of entries into these two chambers were similar in WT mice and Arhgef10 knockout mice (Fig. 2c; $F_{1,22}=1.607, p=0.218$ for genotype $\times$ chamber, by two-way ANOVA).
In the test for social novelty preference, we further examined social recognition in WT and Arhgef10 knockout mice. Mice naturally exhibit a preference for social novelty, spending more time with a new mouse than with a familiar mouse as a social stimulus. In addition to stranger 1 in the original cylinder, another stranger mouse (stranger 2) was placed in the second cylinder. WT mice showed a preference for exploring the compartment with the novel mouse, stranger 2, compared with the chamber containing stranger 1 (Fig. $2 \mathrm{~d}$ and e; $F_{1,22}=5.843, p=0.024$ for genotype $\times$ chamber, by two-way ANOVA; post hoc for comparisons between stranger 1 and stranger 2 revealed $p<0.05, n=12$ for WT, and $p<0.05, n=12$ for KO). Although Arhgef10 knockout mice spent more time in the chamber with the first stranger mouse than in the chamber with the second stranger mouse (Fig. 2d), the time spent in social interactions, such as sniffing or tail rattling or time spent near the cylinder containing the stranger mice was similar between the first and the second stranger mouse (Fig. 2e). Keeping up with the decreased social interaction in sociability test, it was found that the social novelty preference was affected in Arhgef10 knockout mice. However, the longer time spent in the chamber with the first stranger mouse without more social interaction may imply that Arhgef10 knockout mice need more time to become familiar with the stranger mouse during the experiment. Both WT and Arhgef10 knockout mice showed a comparable number of entries into the compartment with stranger 1 and the one with the novel mouse, stranger 2 (Fig. $2 \mathrm{f} ; F_{1,22}=$ $0.983, p=0.602$ for genotype $\times$ chamber, by two-way ANOVA).

\section{Increased locomotor activity in Arhgef10 knockout mice}

The open field test was used to evaluate the general locomotor and exploratory activity of the mice. Arhgef10 knockout mice showed a higher level of locomotor activity in open field $\left(F_{1}, \quad 30=12.296, p=0.001, n=16\right)$ (Fig. 3a). In a 60-min open field test, Arhgef10 knockout mice exhibited significantly enhanced locomotor activity compared with WT mice at 0-5, 30-35, and 45-50 min (Fig. 3b, Tukey's test for multiple comparisons, $p<0.05$ ). There was no significant difference in rearing activity between WT and knockout mice (Fig. 3c). In addition, there was no significant difference between WT and Arhgef10 knockout mice in the amount of activity occurring in the center of the field (Fig. 3d).

\section{Reduction of anxiety-like behavior in Arhgef10 knockout mice}

The EPM was used to measure the level of anxietylike behavior in the mice. The time spent in the open 

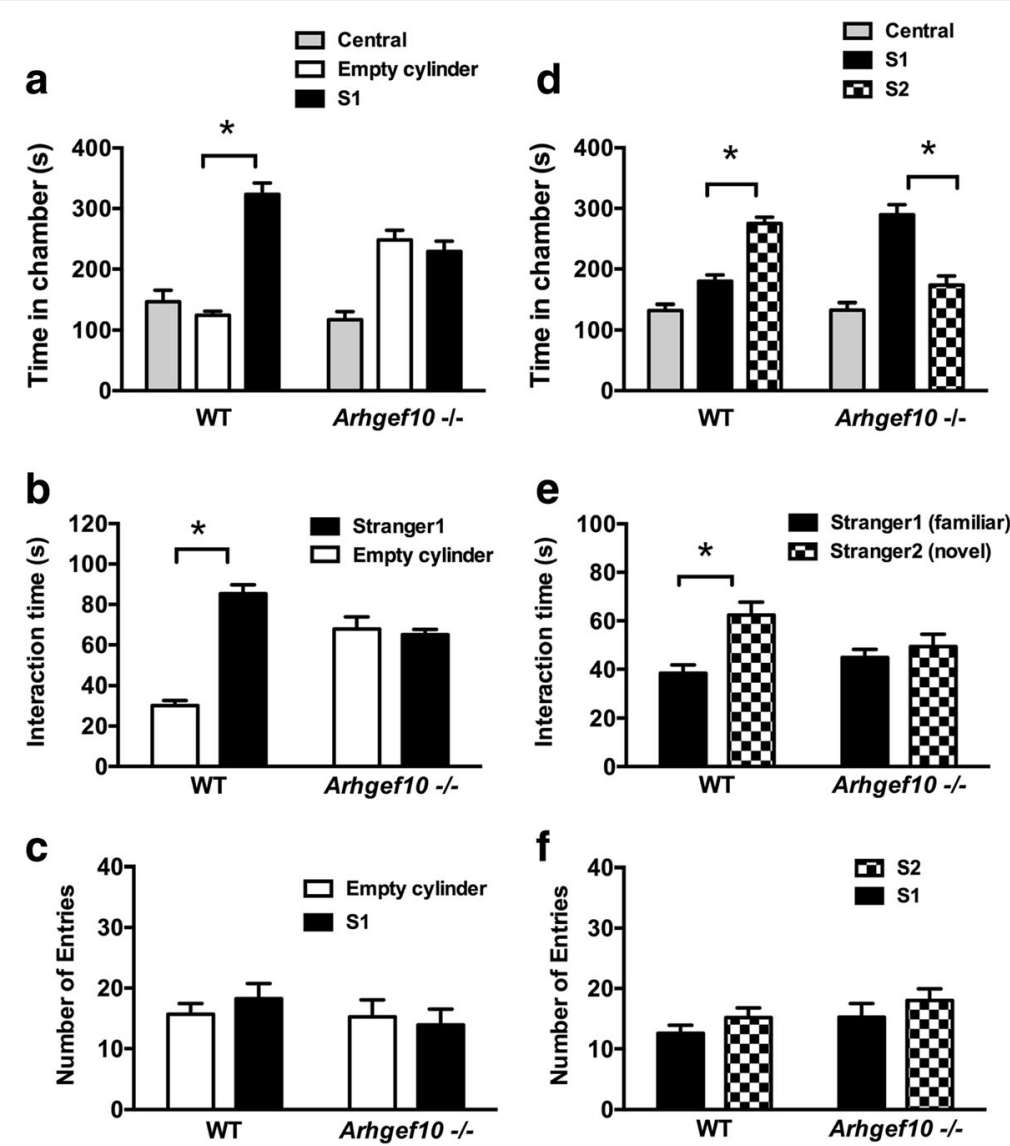

Fig. 2 Arhgef10 knockout mice exhibit social impairment in the three-chamber test. a The time spent in each of the three compartments was analyzed using EthoVision. $\mathbf{b}$ The active interaction times with the empty cylinder and an unfamiliar mouse (stranger 1) in the session were also evaluated. WT mice $(n=12)$ spent much more time in the chamber with stranger 1 than in the empty cylinder, and displayed more interaction with the mouse than with the empty cylinder, indicating normal sociability $(p<0.001)$. However, Arhgef10 $/^{-}$mice $(n=12)$ spent equal durations of both total time and active interaction time in the chamber with empty cylinder and stranger 1 . $\mathbf{d}$ In the preference for social novelty test, the time spent in each chamber was analyzed as in the previous test. WT mice spent more time in the chamber with a novel mouse (stranger 2) than in the compartment with stranger 1. However, Arhgef10 -/- mice spent less time in the chamber with stranger 2 than in the chamber with stranger 1. e The duration of contact time was measured with stranger 1 and the novel mouse stranger 2 . WT mice displayed a significant increase in the duration of close interaction with stranger 2 compared with stranger $1(p<0.001)$. However, Arhgef10 $-/-$ mice did not show a preference for novel stranger 2

arms or closed arms is used as an index to define the level of anxiety-like behavior. It was found that Arhgef10 knockout mice displayed less anxiety-like behavior. The time spent in the open arms was significantly increased in Arhgef10 knockout mice (open arms: $F_{1,23}=11.04, p=$ 0.003; closed arms: $F_{1,23}=14.481, p=0.001, n=13$ for WT vs Arhgef10 KO) (Fig. 4a), indicating that anxiety-like behavior was reduced in knockout mice. Upon analyzing the number of entries into each arm, we found that the number of entries into the open arms was significantly increased in Arhgef10 knockout mice (open arms: $F_{1,23}=$ 6.301, $p=0.02$; closed arms: $F_{1,23}=2.431, p=0.134$ for WT vs Arhgef10 KO) (Fig. 4b). The results demonstrated that there was a reduction of anxiety-like behavior in Arhgef10 KO mice.

\section{Reduction of depression-like behavior in Arhgef10} knockout mice

To further examine whether other mood-related behaviors were also affected in Arhgef10 knockout mice, animals were subjected to the tail suspension test (TST) and the forced swim test (FST). Increased immobility and floating time are indicative of depression-related behavior. Interestingly, Arhgef10 knockout mice showed a significant reduction of immobility in both the FST $(151.1 \pm 9.47 \mathrm{~s}$, and $62.43 \pm 1.5 \mathrm{~s}$ for WT and KO mice, respectively) and TST $(207.0 \pm 6.013 \mathrm{~s}$ and 131.2 \pm 13.47 for WT and KO, respectively) (Fig. 4c, d). The duration of immobility time in both the FST and the TST was significantly shorter in Arhgef10 knockout mice than in WT mice $\left(F_{1,17}=\right.$ $39.175, p<0.0001$ in FST; $F_{1,17}=24.109, p=0.0013$ in 

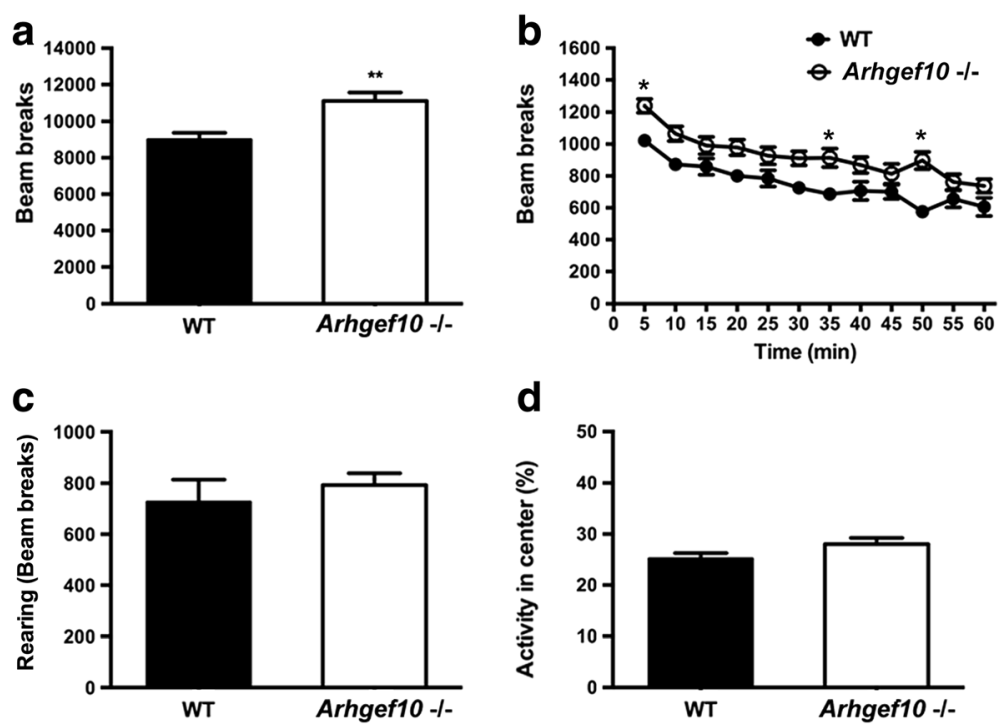

Fig. 3 Arhgef10 knockout mice display spontaneous locomotor hyperactivity in the open field test. Spontaneous locomotor activity was tested in an open field for $60 \mathrm{~min}$. a Total ambulatory locomotion $(p=0.001)$. b Time course of locomotor activity. Note that locomotor activity was greater in Arhgef10 knockout mice. c No difference between WT mice and Arhgef10 ${ }^{-}-$mice in total rearing was observed. $\mathbf{d}$ No difference in percent of activity in the central part of the open field was observed between WT mice and Arhgef10 ${ }^{-}-$mice. The bar graph shows mean \pm SEM ( $n=16$ per genotype for WT mice and KO mice); ${ }^{*} p<0.05$ compared with WT mice by one-way ANOVA

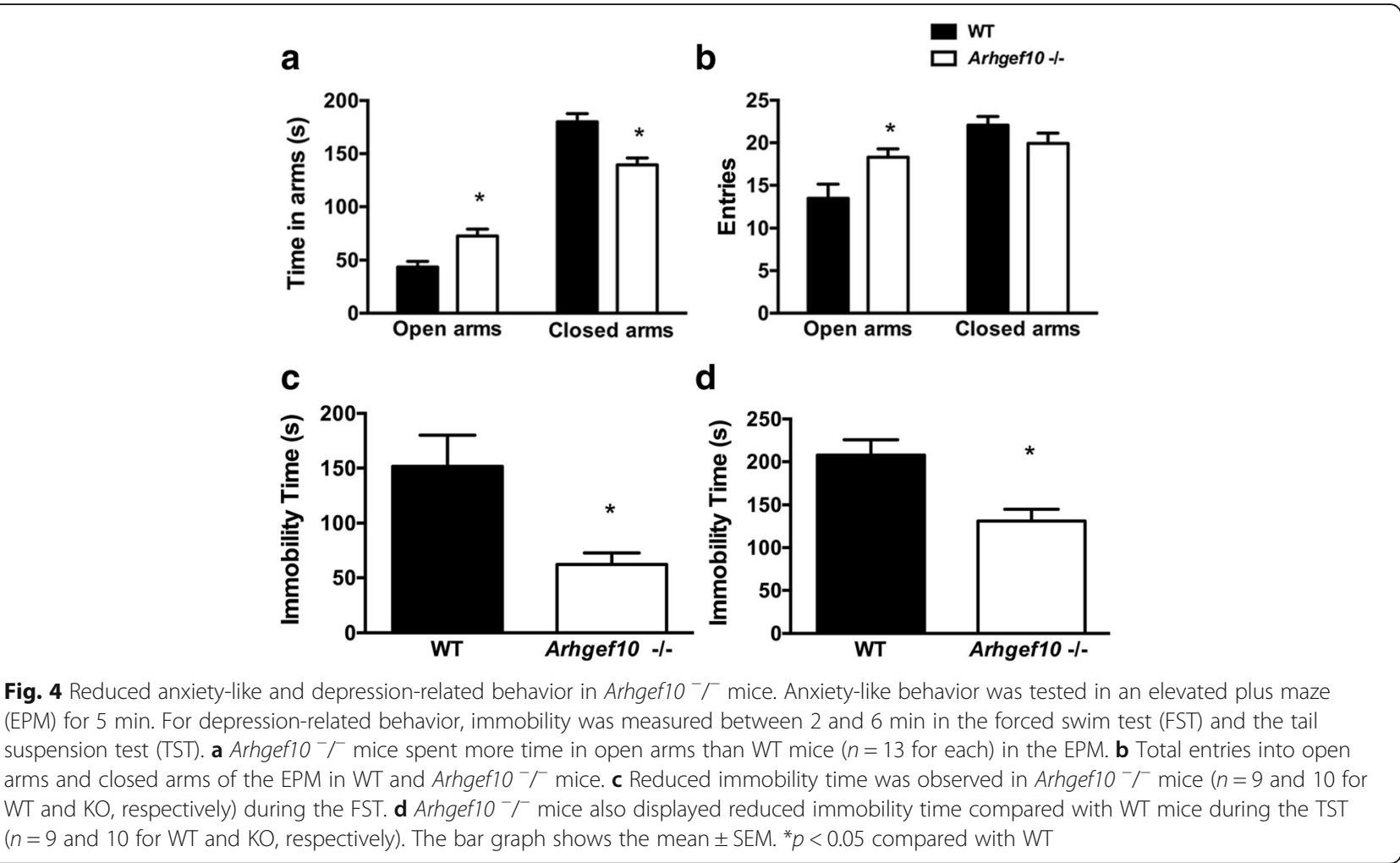


TST; $n=9$ and 10 for WT and $\mathrm{KO}$, respectively). These results indicated that there was reduction of depression-like behavior in Arhgef10 KO mice.

Pre-pulse inhibition is unaffected in Arhgef10 knockout mice The pre-pulse inhibition (PPI) test is used to evaluate sensory gating in mice. Acoustic startle responses provide information on the sensorimotor processes of the animal in response to acoustic stimuli. Arhgef10 knockout mice had a normal startle amplitude in response to $120 \mathrm{~dB}$ acoustic stimuli, indicating that the reflexive contraction of the muscles in response to acoustic stimuli was normal $\left(F_{1.9}=1.171, p=0.337\right.$, $n=5-6)$ (Fig. 5a). Moreover, Arhgef10 knockout mice also exhibited a reduced acoustic startle response when the acoustic startle stimulus was preceded by a weaker acoustic stimulus, indicating a normal PPI response in comparison with WT mice (two-way ANOVA for genotype $\times$ pre-pulse $\mathrm{dB}$, main effect of genotype: $F_{1.9}=1$. 0366, $p=0.8524 ;$ main effect of pre-pulse dB: $F_{2,18}=25.27, p<0.001$.) (Fig. $5 b$ ).

\section{Arhgef10 knockout mice exhibit normal spatial learning in the Morris water maze test \\ Spatial learning behavior was measured using the Morris water maze test. For four training days, Arhgef10 knock- out mice displayed normal learning ability with typical decreases in escape latency $(F=0.260, p=0.618, n=6-$}

7) (Fig. 5c). In the probe test, both WT and Arhgef10 knockout mice spent much more time in the target quadrant than in opposite or adjacent quadrants (Fig. 5d), indicating that Arhgef10 knockout mice exhibited normal spatial learning.

\section{Increased norepinephrine (NE) and serotonin (5-HT) levels} in the frontal cortex and amygdala of Arhgef10 knockout mice

To further explore the possible underlying mechanisms leading to the behavioral changes caused by functional loss of ARHGEF10, we investigated the neurochemical composition of different brain regions of Arhgef10 knockout mice. The frontal cortex, striatum, hippocampus, and amygdala from WT and KO mice were analyzed by HPLC with electrochemical detection (ECD) to determine the content of dopamine, 5-HT, NE, and their metabolites. The content of NE in the frontal cortex and amygdala was significantly elevated in Arhgef10 knockout mice (two-way ANOVA for genotype $\times$ brain regions, main effect of genotype: $F_{1,10}=6.776, p=0.0264$ and brain regions $F_{3}$, $30=3.250, \quad p=0.0354 ;$ interaction: $F_{3}, \quad 30=2.764, p=$ 0.0591). Post hoc comparisons between WT and KO revealed significant differences in the frontal cortex and amygdala (Fig. 6a). Serotonin content in the amygdala and hippocampus was also increased in Arhgef10 knockout mice compared with WT mice (two-way ANOVA for genotype $\times$ brain regions, main effect of genotype: $F_{1,10}=$
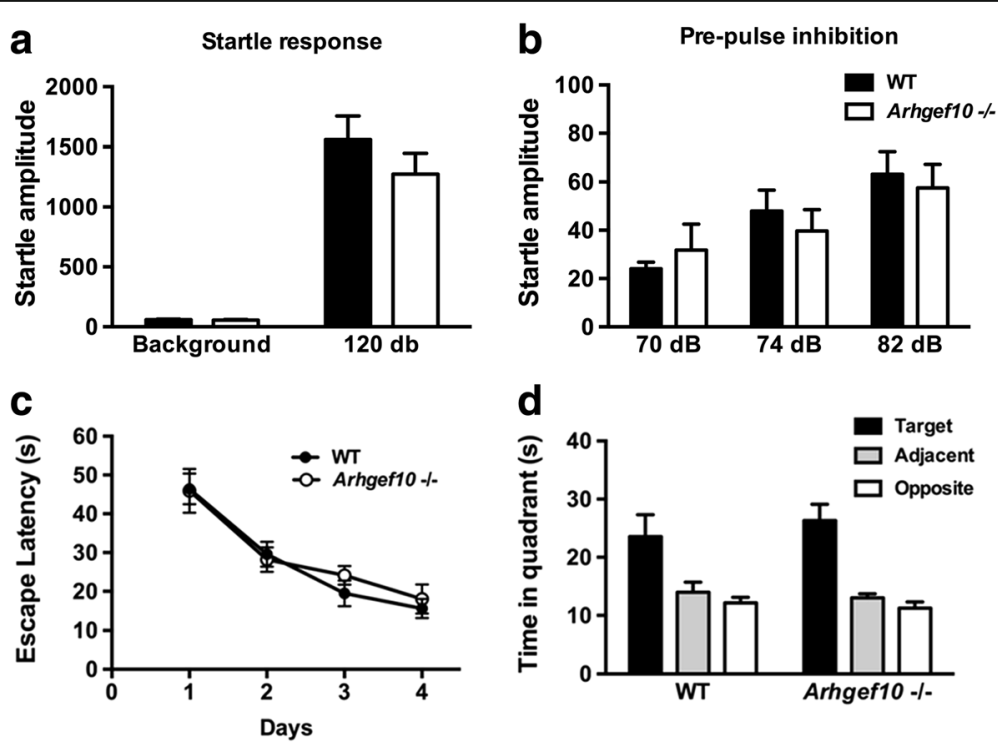

Fig. 5 Arhgef10 knockout does not affect the startle response, pre-pulse inhibition (PPI) or learning. The startle reflex response was measured as startle amplitude, and PPI is the reduction of this response when an acoustic startle (120 dB) is preceded by a stimulus of 70, 74, or $82 \mathrm{~dB}$. a There was no difference between WT and Arhge ${ }^{f 1} \mathrm{O}^{-} J^{-}$mice in startle responses to a 120-dB acoustic stimulus. $\mathbf{b}$ Arhgef10 ${ }^{-}{ }^{-}$mice did not show a PPI deficit for a pre-pulse of 70,74 , or $82 \mathrm{~dB}(n=5-6)$. $\mathbf{c}$ In the Morris water maze test, all mice were trained for 4 days to reach the platform. $\mathbf{d}$ On day 5 , the platform was removed for the probe test to examine the memory of the animals. Note that Arhgef $10^{-}{ }^{-}$mice exhibit the same normal acquisition curve as WT mice. Both WT and Arhgef10 ${ }^{-}$- mice spent much more time in the target zone than in any other zone in the probe test. The bar graph shows the mean $\pm \operatorname{SEM}(n=6-7)$. ${ }^{*} p<0.05$ compared with adjacent or opposite quadrants 


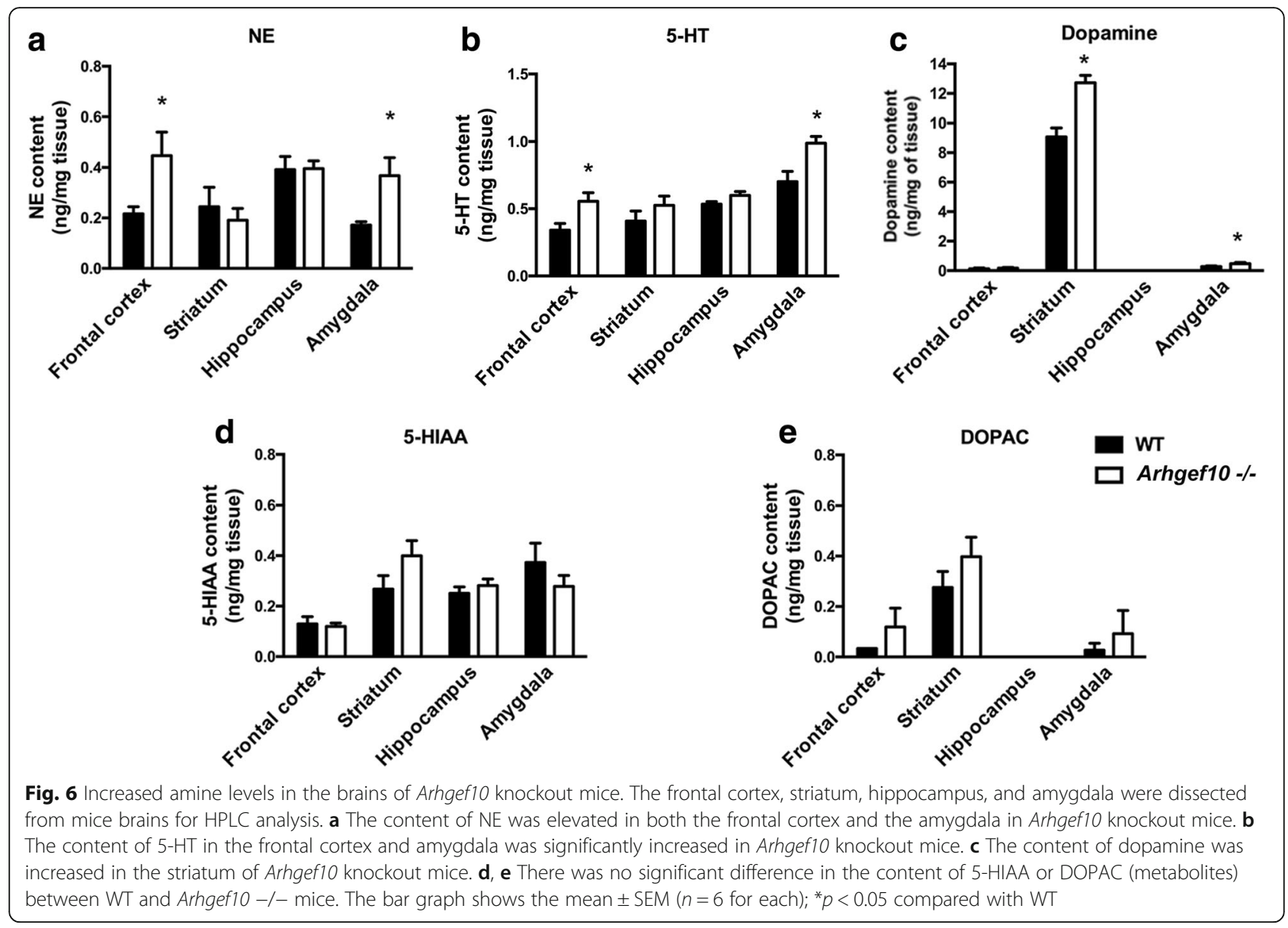

11.57, $p=0.0068$ and brain regions $\left(F_{3}, 30=24.650\right.$, $p<0.0001$; interaction: $\left.F_{3,30}=1.814, p=0.1659\right)$. Post hoc comparisons between WT and $\mathrm{KO}$ revealed significant differences in the frontal cortex and amygdala. Dopamine in the striatum was also increased in Arhgef10 knockout mice compared with WT mice (two-way ANOVA for genotype $\times$ brain regions, main effect of genotype: $F_{1,10}=$ 23.47, $p=0.0007$ and brain regions $F(3,30)=731.5$, $p<0.0001$; interaction: $\left.F_{3,30}=20.36, p<0.0001\right)$. Post hoc comparisons between $\mathrm{WT}$ and $\mathrm{KO}$ revealed a significant difference in the striatum (Fig. 6c). However, there were no differences in the metabolites of these monoamines between WT and Arhgef10 knockout mice (Fig. 6d, e).

\section{Reduction of MAO-A expression in Arhgef10 knockout mice}

Since NE and 5-HT levels were significantly elevated in Arhgef10 knockout mice, we measured the expression of MAO-A and MAO-B, the key enzymes that degrade NE and $5-\mathrm{HT}$, in the corresponding brain areas using Western blotting. MAO-A levels between WT and Arhgef10 knockout mice were evaluated by two-way ANOVA (two-way ANOVA for genotype $\times$ brain regions, main effect of genotype: $F_{1,12}=4.305, p=0.0602$ and brain regions $F_{3}, 36=2.286, p=0.0953$; interaction: $F_{3}, 36=$ 2.324, $p=0.0913)$. Post hoc comparisons between WT and $\mathrm{KO}$ revealed significant differences in frontal cortex and amygdala. Further comparison of these differences found significantly reduced MAO-A levels in the frontal cortex and amygdala (Fig. 7a). In contrast with MAO-A levels, no statistically significant difference was found in MAO-B levels between WT and Arhgef10 knockout mice (two-way ANOVA for genotype $\times$ brain regions, main effect of genotype: $F_{1,4}=3.163, P=0.1499$ and brain regions $F_{3}, 12=2.688, p=0.0934$; interaction: $F_{3,12}=$ $0.3990, p=0.7563$ ) (Fig. 7b). Furthermore, we also examined the enzymes dopamine $\beta$-hydroxylase $(\mathrm{DBH})$ and tryptophan hydroxylase (TPH), which are involved in the synthesis of NE and 5-HT, respectively. WT and Arhgef10 knockout mice had similar protein levels of both DBH (two-way ANOVA for genotype $\times$ brain regions, main effect of genotype: $F_{1,4}=0.03559$, $p=0.8595$ and brain regions $F_{3,12}=7.614, p=0.0041$; interaction: $F_{3}, 12=0.2854, p=0.8350$ ) and TPH (twoway ANOVA for genotype $\times$ brain regions, main effect of genotype: $F_{1,4}=0.5692, p=0.4926$ and brain regions $F_{3,12}=6.591, p=0.0070$; interaction: $F_{3}, 12=1.190$, $P=0.3549$ ) in the tested brain regions (Fig. 7c, d). 

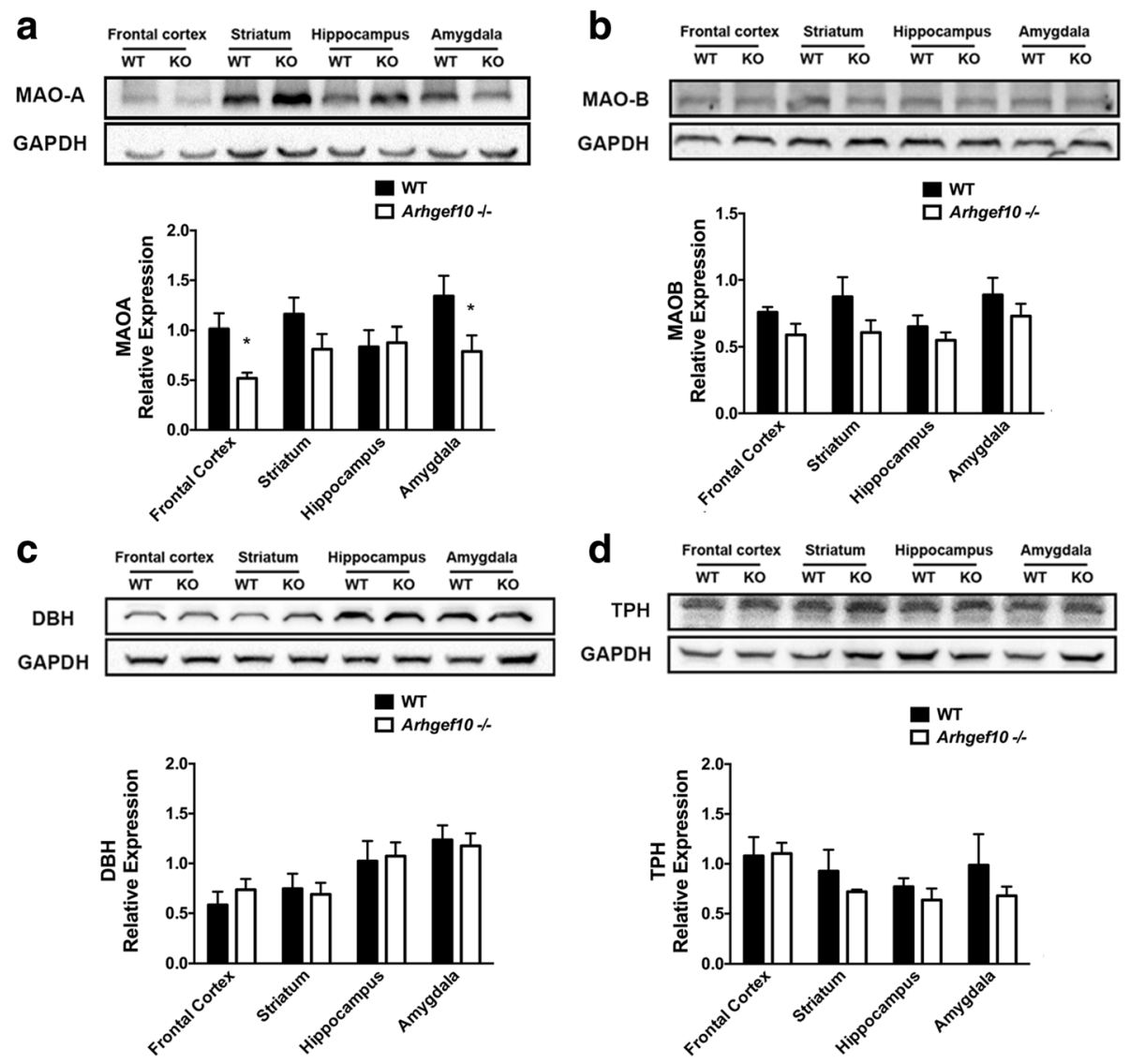

Fig. 7 MAO-A is decreased in Arhgef10 ${ }^{-/}$mice. The main degradation enzymes 5-HT and NE were analyzed by Western blotting. a MAO-A expression was decreased in the frontal cortex and amygdala of Arhgef10 ${ }^{-}{ }^{-}$mice. Another metabolizing enzyme, MOA-B, did not show a significant difference between WT and KO mice $\mathbf{b}$. The main enzymes for the synthesis of the amine neurotransmitters were also analyzed by Western blotting. The protein levels of both $\mathrm{DBH} \mathbf{c}$ and TPH $\mathbf{d}$ were similar between WT and KO mice in the examined brain areas. ${ }^{*} p<0.05$ compared with WT. MAO-A monoamine oxidase A, MAO-B monoamine oxidase B, DBH dopamine $\beta$-hydroxylase, TPH tryptophan hydroxylase

\section{Discussion}

In a previous clinical study, we found a terminal deletion containing the gene ARHGEF10 on chromosome 8 in autistic patients. The current study demonstrates that loss of function of Arhgef10 leads to impairment of social behavior and altered mood-related behavior in mice. Importantly, Arhgef10 knockout mice showed indifference toward the novel objects and stranger mice in the free social interaction assay, as well as a lack of preference between the novel mouse and the familiar mouse during the social recognition test. Overall, Arhgef10 knockout mice displayed no preference between the empty chamber and stranger mouse 1 and showed no preference for social interaction with the novel mouse, stranger 2. These results indicate that ARHGEF10 deficiency might cause a deficit in social interaction and social recognition. Interestingly, although Arhgef10 knockout mice stayed longer in the chamber with the first stranger mouse than the chamber with the second stranger mouse (Fig. 2d), there was no difference in the time of social interaction between the two chambers containing stranger mice (Fig. 2e). These results suggest that Arhgef10 knockout mice lacked interest in interaction with stranger mice. Moreover, Arhgef10 knockout mice exhibited a decreased tendency to explore the area with the second mouse. This decreased tendency to investigate the area with a novel stranger mouse may correlate with an aloof character typical of autism. The reduced social interaction and lack of preference for social novelty observed in the three-chamber social behavior tests support our speculation that the deletion of ARHGEF10 might partly be correlated with clinical manifestations in individuals with ASD.

Several published observations have shown that children with ASD are at a high risk of anxiety disorders [21]. In this study, a reduced anxiety level was found in knockout mice, compared with WT mice, in the EPM test. Arhgef10 knockout mice spent a longer duration in 
the open arms than WT mice, implying reduced anxiety-like behavior in Arhgef10 knockout mice. Moreover, the reduced anxiety-like behavior in EPM could result from the decreased innate fear responses to elevated and open areas. Additionally, Arhgef10 knockout mice entered the open arm more frequently than WT, which suggests Arhgef10 deficiency did not affect the natural tendency to explore novel places. However, in the three-chamber test, the tendency to investigate the place with a novel stranger was reduced in Arhgef10 knockout mice, indicating possible social withdrawal behavior. Although the finding of a lower level of anxiety in Arhgef10 knockout mice is inconsistent with another reported autism-like mouse strains [22, 23], the reduced anxiety in Arhgef10 knockout mice indicates that social interaction defects were not caused by anxiety-like behavior. The reduction of anxiety-like behavior strengthened the correlation between Arhgef10 and social behavior and suggests the involvement of Arhgef10 in anxiety-related behavior.

We further evaluated specific depression-like behavior using the FST and the TST, to verify that social deficits in Arhgef10 knockout mice are not caused by depression-related effects. Compared with WT mice, Arhgef10 knockout mice exhibited lower immobility time in the FST and the TST than WT mice, suggesting that Arhgef10 KO reduces depression-like behavior. These results revealed that ARHGEF10 is also involved in the regulation of depression-like behavior. The lower levels of anxiety-like and depression-like behavior further demonstrated that the social traits in Arhgef10 knockout mice were not the results of mood-related behavioral abnormalities. In addition, Arhgef10 knockout mice exhibited enhanced locomotor activity in a novel open field, which might be a reflection of the hyperactivity that is often observed clinically in autistic patients. The features of hyperactivity have also been reported in other animal models of autism [24-26]. Although Arhgef10 knockout mice displayed characteristic hyperactivity, the number of entries into each compartment was not increased in the three-chamber tests, indicating that the reduced social behavior was not a result of hyperactivity. When the results of social impairment and hyperactivity are taken together, the ASD-associated social inability observed in the Arhgef10 deficiency mice appears not to result from low levels of spontaneous activity. The reduced anxiety-like behavior and hyperactivity phenotype observed in Arhgef10 knockout mice may be a sign of increased impulsive behavior. We thus further evaluated impulsive behavior using the electro-foot shock aversive water drinking test (EFSDT) [27]. Arhgef10 knockout mice displayed no obvious impulsive behaviors in comparison with WT mice (Additional file 2: Figure S2-2).
Although some studies suggest that autism features sensorimotor deficits [28], we did not find any PPI deficit in Arhgef10 knockout mice. No abnormalities were found in the startle response or sensory gating, indicating that the Arhgef10 knockout does not affect the sensory gating system in mice. Moreover, escape latencies were comparable between WT and Arhgef10 knockout mice in the Morris water maze, suggesting that the deletion of ARHGEF10 does not impair spatiallearning-based behavior.

Social behavior can be affected by many behavioral factors, including anxiety levels, spontaneous activity, depression, sensory perception, memory, and cognition. Arhgef10 knockout mice displayed normal sensorimotor responses in the PPI test and normal spatial learning behavior in the water maze. Moreover, Arhgef10 knockout mice did not exhibit depression-like or anxiety-like behavior, suggesting that the social deficit was not confounded by these factors. Our study demonstrated that the loss of function of ARHGEF10 mainly caused social impairment in mice.

In this study, changes in neurotransmitter levels were observed as well. Serotonin and norepinephrine levels were significantly increased in the frontal cortex and amygdala of Arhgef10 knockout mice. The amygdala has been implicated in various functions concerning emotion and social behavior. Several studies in primates and other mammalian species have implicated the amygdala as an important contributor to social behavior [29, 30]. Neonatal lesions of the amygdala in rats results in a social behavior deficit, and these rats exhibit autistic-like symptoms [31]. Furthermore, an early bilateral lesion of the amygdala in rhesus monkeys leads to reduced social interactions with other monkeys [32]. On the basis of the biological function of the amygdala, it is proposed to be one of the main regulatory brain regions driving the pathology of ASD [33]. Furthermore, the frontal cortex is the region responsible for emotion control and decision making and has been reported to be associated with the cognitive and anatomical abnormalities in patients with autism [34]. Based on the distinctive roles of the frontal cortex and amygdala in autism, the neurochemical changes in these brain regions may be linked to the observed phenomena in Arhgef10 knockout mice. The neurochemical study of autism began with a report of changes in serotonin [35]. An elevated serotonin level in whole blood is a wellcharacterized biomarker in autism research [6]. Additionally, increased serotonin synthesis capacity has been reported in autistic children, suggesting that serotonin may play an important role in the development of autism [36]. The elevated serotonin levels found in the brains of Arhgef10 knockout mice correlate with attenuated depressionlike behaviors observed in the FST and the TST. These findings also support the role of the serotonin system in 
some autism patient symptoms. Apart from serotonin, norepinephrine is also an important monoamine associated with neuronal functions and levels of anxiety, arousal, and stress sensitivity, and many of these functions are also impaired in ASD. Evidence for involvement of norepinephrine in ASD comes from a report indicating that patients with autism and their families showed elevated plasma levels of NE and low enzyme activity [37]. The Angelman syndrome mouse model, which exhibits autistic-like behavior, shows increased norepinephrine and serotonin levels in different brain regions [23]. In addition, the elevated serotonin level in brain found in Arhgef 10 knockout mice can also explain their attenuated depression-like behaviors in the FST and the TST. The changes of serotonin and norepinephrine in the frontal cortex and amygdala indicate that ARHGEF10 might play a role in linking the phenotype of social impairment to the balance of monoamines. Therefore, the loss of homeostasis of serotonin and norepinephrine in the frontal cortex and amygdala of the Arhgef10 knockout mice might be the basis of their autistic-like behaviors.

We sought to further understand the underlying mechanisms that contribute to the increased level of amine neurotransmitters. Therefore, we examined MAO-A and MOA-B, which are the key enzymes responsible for catalyzing the metabolism of monoamines, including serotonin and norepinephrine. In addition, the enzymes dopamine $\beta$-hydroxylase (DBH), and tryptophan hydroxylase (TPH), which are responsible for the synthesis of norepinephrine and serotonin, respectively, were also examined using Western blot. MAO-A was decreased in the frontal cortex and amygdala in Arhgef10 knockout mice. However, the levels of DBH and TPH were comparable to those of WT littermates, indicating that the synthesis of the corresponding neurotransmitters was not affected by the Arhgef10 knockout. The lower level of MAO-A may reduce the capacity for serotonin and NE degradation. The decreased MAO-A in Arhgef10 knockout mice provides a possible explanation for the higher levels of serotonin and norepinephrine in the frontal cortex and amygdala. Recently, a study demonstrated that patients with autism had decreased MAO-A activity in the frontal cortex and cerebellum [38]. Moreover, mice lacking MAO-A displayed increased serotonin and norepinephrine levels and aggressive behavior [39]. Another knockout mouse lacking MAO-A/B also exhibited elevated serotonin levels and autistic-like features [40]. These previous reports support our findings in Arhgef10 knockout mice, which implied that the reduced MAO-A levels and elevated amine levels might be the causes of social impairment. Although the phenotypes might result from changes in amine levels in the frontal cortex and amygdala, further study of the neurotransmitters and related molecules that are regulated by ARHGEF10 is required to clarify the underlying mechanism.

\section{Conclusion}

In conclusion, this study demonstrated the behavioral and neurochemical changes of Arhgef10 knockout mice. These mice exhibited social inability in the threechamber test, reflecting the social impairment observed in humans with ASD. On the other hand, ARHGEF10 knockout mice displayed hyperactivity in the locomotor test, reduced anxiety-like behavior in the EPM, and reduced depression-like behavior in the FST and TST. These behavioral changes further confirmed that the social deficits in Arhgef10 knockout mice were not confounded by mood disorders. Moreover, neurochemical changes such as elevated serotonin and norepinephrine levels were also found in the frontal cortex and amygdala in Arhgef10 knockout mice. Further analysis of MAO-A and MAO-B, the key enzymes that degrade norepinephrine and serotonin, revealed that the loss of function of ARHGEF10 decreased the expression of MAO-A in the frontal cortex and amygdala. These results suggest that ARHGEF10 is a risk gene for ASD, especially correlated with the symptom of social activity impairment.

\section{Additional file}

Additional file 1: Generation of ARHGEF10 -/- mice. (PPTX $46 \mathrm{~kb}$ )

Additional file 2: Impulsive and Non-impulsive behavior. (PDF 15155 kb)

\section{Abbreviations}

5-HT: Serotonin; ARHGEF10: A rho guanine nucleotide exchange factor 10; ASD: Autism spectrum disorder; CNV: Copy number variation;

DBH: Dopamine ß-hydroxylase; EFSDT: Electro-foot shock aversive water drinking test; EPM: Elevated plus maze; FST: Forced swimming test; GAPDH: Glyceraldehyde-3-phosphate dehydrogenase; GEF: Guanine nucleotide exchange factor; KO: Knockout; MAO-A: Monoamine oxidase A; MAO-B: Monoamine oxidase B; NE: Norepinephrine; PPI: Pre-pulse inhibition; TPH: Tryptophan hydroxylase; TST: Tail suspension test; WT: Wild-type

\section{Acknowledgements}

Not applicable

\section{Funding}

This work was supported by the National Science Council (NSC 99-3112-B002-036 and NSC 101-2314-B-002-136-MY3), Taiwan, National Taiwan University (AIM for Top University Excellent Research Project, 10R81918-

03,101R892103, 102R892103, 103R892103), and Ministry of Science and Technology (MOST 105-2321-B-002-020), Taiwan. We thank the technical services provided by the Transgenic Mouse Model Core Facility of the National Core Facility Program for Biotechnology, the National Science Council, and the Gene Knockout Mouse Core Laboratory of National Taiwan University Center for Genomic Medicine.

\section{Availability of data and materials}

The datasets presented in this study can be made available on reasonable request. 


\section{Authors' contributions}

SS-FG initiated this research. SS-FG, H-ML, and C-HC generated and verified the mutant mice. D-HL and W-MF designed the experiments in this paper. $\mathrm{D}-\mathrm{HL}, \mathrm{H}-\mathrm{JT}$, and $\mathrm{H}-\mathrm{CL}$ performed the experiments. D-HL analyzed the data. DHL, H-ML, W-MF, and SS-FG interpreted the results. D-HL drafted the manuscript. H-ML, W-MF, and SS-FG revised the manuscript. SS-FG and W-MF supervised the studies and edited the manuscript for resubmission. All the authors approved the final version of the manuscript.

\section{Ethics approva}

All animal experiments were approved by the Ethical Committee for Animal Research of the National Taiwan University.

\section{Consent for publication}

Not applicable

\section{Competing interests}

The authors declare no competing finance interests.

\section{Publisher's Note}

Springer Nature remains neutral with regard to jurisdictional claims in published maps and institutional affiliations.

\section{Author details}

'Pharmacological Institute, College of Medicine, National Taiwan University, Taipei, Taiwan. ${ }^{2}$ Department of Psychiatry, National Taiwan University Hospital and College of Medicine, Taipei, Taiwan. ${ }^{3}$ Department of Psychiatry, Chang Gung Memorial Hospital Linkou, Taoyuan, Taiwan. ${ }^{4}$ Department and Graduate Institute of Biomedical Sciences, Chang Gung University, Taoyuan, Taiwan.

Received: 19 June 2017 Accepted: 25 January 2018

Published online: 13 February 2018

\section{References}

1. American Psychiatric Association. Diagnostic and statistical manual of mental disorders. Fifth ed. Arlington: American Psychiatric Association; 2013.

2. Yin $\mathrm{CL}$, Chen HI, Li LH, Chien YL, Liao HM, Chou MC, et al. Genome-wide analysis of copy number variations identifies PARK2 as a candidate gene for autism spectrum disorder. Mol Autism. 2016;7:23. https://doi.org/10.1186/ s13229-13016-10087-13227. eCollection 12016

3. Werling DM, Geschwind DH. Sex differences in autism spectrum disorders. Curr Opin Neurol. 2013;26:146-53.

4. Baxter AJ, Brugha TS, Erskine HE, Scheurer RW, Vos T, Scott JG. The epidemiology and global burden of autism spectrum disorders. Psychol Med. 2015;45:601-13.

5. Lyall K, Croen L, Daniels J, Fallin MD, Ladd-Acosta C, Lee BK, et al. The Changing Epidemiology of Autism Spectrum Disorders. Annu Rev Public Health. 2017:38:81-102.

6. Ruggeri B, Sarkans U, Schumann G, Persico AM. Biomarkers in autism spectrum disorder: the old and the new. Psychopharmacology. 2014;231: 1201-16.

7. Chien WH, Gau SS, Wu YY, Huang YS, Fang JS, Chen YJ, et al. Identification and molecular characterization of two novel chromosomal deletions associated with autism. Clin Genet. 2010;78:449-56.

8. Jiang-Xie LF, Liao HM, Chen CH, Chen YT, Ho SY, Lu DH, et al. Autismassociated gene Dlgap2 mutant mice demonstrate exacerbated aggressive behaviors and orbitofrontal cortex deficits. Mol Autism. 2014;5:32. https:// doi.org/10.1186/2040-2392-1185-1132. eCollection 2014

9. Chien WH, Gau SS, Liao HM, Chiu YN, Wu YY, Huang YS, et al. Deep exon resequencing of DLGAP2 as a candidate gene of autism spectrum disorders. Mol Autism. 2013;4:26. https://doi.org/10.1186/2040-2392-1184-1126.

10. Verhoeven K, De Jonghe P, Van de Putte T, Nelis E, Zwijsen A, Verpoorten N, et al. Slowed conduction and thin myelination of peripheral nerves associated with mutant rho Guanine-nucleotide exchange factor 10. Am J Hum Genet. 2003;73:926-32.

11. Jungerius BJ, Hoogendoorn ML, Bakker SC, Van't Slot R, Bardoel AF, Ophoff RA, et al. An association screen of myelin-related genes implicates the chromosome 22q11 PIK4CA gene in schizophrenia. Mol Psychiatry. 2008;13:1060-8.
12. Stankiewicz TR, Linseman DA. Rho family GTPases: key players in neuronal development, neuronal survival, and neurodegeneration. Front Cell Neurosci. 2014;8:314.

13. Kutsche $\mathrm{K}$, Yntema $\mathrm{H}$, Brandt $\mathrm{A}$, Jantke I, Nothwang HG, Orth $\mathrm{U}$, et al. Mutations in ARHGEF6, encoding a guanine nucleotide exchange factor for Rho GTPases, in patients with X-linked mental retardation. Nat Genet. 2000;26:247-50.

14. Lam KS, Aman MG, Arnold LE. Neurochemical correlates of autistic disorder: a review of the literature. Res Dev Disabil. 2006;27:254-89.

15. Tassone F, Qi L, Zhang W, Hansen RL, Pessah IN, Hertz-Picciotto I. MAOA, DBH, and SLC6A4 variants in CHARGE: a case-control study of autism spectrum disorders. Autism Res. 2011;4:250-61.

16. Chakraborti B, Verma D, Karmakar A, Jaiswal P, Sanyal A, Paul D, et al. Genetic variants of MAOB affect serotonin level and specific behavioral attributes to increase autism spectrum disorder (ASD) susceptibility in males. Prog Neuro-Psychopharmacol Biol Psychiatry. 2016;71:123-36.

17. Kadar A, Wittmann G, Liposits Z, Fekete C. Improved method for combination of immunocytochemistry and Nissl staining. J Neurosci Methods. 2009:184:115-8.

18. Moy SS, Nadler JJ, Perez A, Barbaro RP, Johns JM, Magnuson TR, et al. Sociability and preference for social novelty in five inbred strains: an approach to assess autistic-like behavior in mice. Genes Brain Behav. 2004;3: 287-302.

19. Li J, Chai A, Wang L, Ma Y, Wu Z, Yu H, et al. Synaptic P-Rex1 signaling regulates hippocampal long-term depression and autism-like social behavior. Proc Natl Acad Sci U S A. 2015;112:E6964-72.

20. Cryan JF, Markou A, Lucki I. Assessing antidepressant activity in rodents: recent developments and future needs. Trends Pharmacol Sci. 2002;23: $238-45$.

21. van Steensel FJ, Bogels SM, Perrin S. Anxiety disorders in children and adolescents with autistic spectrum disorders: a meta-analysis. Clin Child Fam Psychol Rev. 2011;14:302-17.

22. McFarlane HG, Kusek GK, Yang M, Phoenix JL, Bolivar VJ, Crawley JN. Autism-like behavioral phenotypes in BTBR T+tf/J mice. Genes Brain Behav. 2008;7:152-63.

23. Farook MF, DeCuypere M, Hyland K, Takumi T, LeDoux MS, Reiter LT. Altered serotonin, dopamine and norepinepherine levels in 15q duplication and Angelman syndrome mouse models. PLoS One. 2012;7:e43030.

24. Penagarikano O, Abrahams BS, Herman El, Winden KD, Gdalyahu A, Dong H, et al. Absence of CNTNAP2 leads to epilepsy, neuronal migration abnormalities, and core autism-related deficits. Cell. 2011:147:235-46.

25. Radyushkin K, Hammerschmidt K, Boretius S, Varoqueaux F, El-Kordi A, Ronnenberg $A$, et al. Neuroligin-3-deficient mice: model of a monogenic heritable form of autism with an olfactory deficit. Genes Brain Behav. 2009:8:416-25.

26. Schmeisser MJ, Ey E, Wegener S, Bockmann J, Stempel AV, Kuebler A, et al. Autistic-like behaviours and hyperactivity in mice lacking ProSAP1/Shank2. Nature. 2012;486:256-60

27. Yang MT, Lu DH, Chen JC, Fu WM. Inhibition of hyperactivity and impulsivity by carbonic anhydrase inhibitors in spontaneously hypertensive rats, an animal model of ADHD. Psychopharmacology. 2015;232:3763-72.

28. Perry W, Minassian A, Lopez B, Maron L, Lincoln A. Sensorimotor gating deficits in adults with autism. Biol Psychiatry. 2007:61:482-6.

29. Amaral DG. The amygdala, social behavior, and danger detection. Ann N Y Acad Sci. 2003;1000:337-47.

30. Adolphs R, Tranel D, Damasio AR. The human amygdala in social judgment. Nature. 1998:393:470-4.

31. Diergaarde L, Gerrits MA, Stuy A, Spruijt BM, van Ree JM. Neonatal amygdala lesions and juvenile isolation in the rat: differential effects on locomotor and social behavior later in life. Behav Neurosci. 2004;118:298-305.

32. Moadab G, Bliss-Moreau E, Bauman MD, Amaral DG. Early amygdala or hippocampus damage influences adolescent female social behavior during group formation. Behav Neurosci. 2017;131:68-82.

33. Baron-Cohen S, Ring HA, Bullmore ET, Wheelwright S, Ashwin C, Williams SC. The amygdala theory of autism. Neurosci Biobehav Rev. 2000;24:355-64.

34. Carper RA, Courchesne E. Inverse correlation between frontal lobe and cerebellum sizes in children with autism. Brain. 2000;123(Pt 4):836-44.

35. Schain RJ, Freedman DX. Studies on 5-hydroxyindole metabolism in autistic and other mentally retarded children. J Pediatr. 1961;58:315-20.

36. Chugani DC. Role of altered brain serotonin mechanisms in autism. Mol Psychiatry. 2002;7(Suppl 2):S16-7. 
37. Lake CR, Ziegler MG, Murphy DL. Increased norepinephrine levels and decreased dopamine-beta-hydroxylase activity in primary autism. Arch Gen Psychiatry. 1977;34:553-6.

38. Gu F, Chauhan V, Chauhan A. Monoamine oxidase-A and B activities in the cerebellum and frontal cortex of children and young adults with autism. J Neurosci Res. 2017:95:1965-1972.

39. Cases O, Seif I, Grimsby J, Gaspar P, Chen K, Pournin S, et al. Aggressive behavior and altered amounts of brain serotonin and norepinephrine in mice lacking MAOA. Science. 1995;268:1763-6.

40. Bortolato M, Godar SC, Alzghoul L, Zhang J, Darling RD, Simpson KL, et al. Monoamine oxidase $\mathrm{A}$ and $\mathrm{A} / \mathrm{B}$ knockout mice display autistic-like features. Int J Neuropsychopharmacol. 2013;16:869-88.

Submit your next manuscript to BioMed Central and we will help you at every step:

- We accept pre-submission inquiries

- Our selector tool helps you to find the most relevant journal

- We provide round the clock customer support

- Convenient online submission

- Thorough peer review

- Inclusion in PubMed and all major indexing services

- Maximum visibility for your research

Submit your manuscript at www.biomedcentral.com/submit
Biomed Central 